\title{
Incorporação de Óleo Essencial de Origanum vulgare L. em Filmes A Base de Quitosana Como Alternativa Para Inibição de Rhizopus stolonifer em Tomates do Tipo Cereja (Lycopersicon esculentum Var. cerasiforme)
}

Jessica Bezerra dos Santos Rodrigues (I), Ana Júlia Alves Aguiar Athayde (II,I), Ingrid Conceição Dantas Guerra (I), Nereide Serafim Timóteo dos Santos (III), Priscila Dinah Oliveira (I), Evandro Leite de Souza (I)

(I) UFPB - Universidade Federal da Paraíba (Cidade Universitária - João Pessoa - PB - Brasil CEP: 58051-900), (II) UFPE - Universidade Federal de Pernambuco (Av. Prof. Moraes Rego, 1235 - Cidade Universitária, Recife - PE - CEP: 50670-901), (III) IFPI - Instituto Federal de Educação, Ciência e Tecnologia do Piauí (Reitoria - Praça da Liberdade, 1597, 64000-040,

Centro, Teresina (PI).)

\section{Resumo}

As doenças pós-colheita são responsáveis por perdas, em muitos casos, superiores a 50\%, perdas essas que ocorrem nas etapas pós-colheita, ou seja, antes de chegar à mesa do consumidor. Grande parte desses prejuízos são causados em decorrência da ação de fungos fitopatógenos. O controle das doenças e pragas na agricultura tem se intensificado, sendo realizado basicamente através do emprego de produtos sintéticos, como agrotóxicos, que têm causado resistência dos organismos, demandando uma quantidade cada vez maior, levando a sérios riscos ambientais e de saúde da população. O presente estudo propôs avaliar a eficácia da aplicação combinada de quitosana e do óleo essencial de orégano ( Origanum vulgare L.), como compostos antimicrobianos naturais, alternativos para a inibição de Rhizopus stolonifer 'in vitro' e em tomates do tipo cereja (Lycopersicon esculentum var. cerasiforme). A Concentração Inibitória Mínima da quitosana e do óleo, foi obtida pela técnica de diluição seriada e para o

\footnotetext{
Referência:

Jessica Bezerra dos Santos Rodrigues, Ana Júlia Alves Aguiar Athayde, Ingrid Conceição Dantas Guerra, Nereide Serafim Timóteo dos Santos, Priscila Dinah Oliveira, Evandro Leite de Souza. Incorporação de Óleo Essencial de Origanum vulgare L. em Filmes A Base de Quitosana Como Alternativa Para Inibição de Rhizopus stolonifer em Tomates do Tipo Cereja (Lycopersicon esculentum var. cerasiforme). In: Anais do 12 Congresso Latinoamericano de Microbiologia e Higiene de Alimentos - MICROAL 2014 [= Blucher Food Science Proceedings, num.1, vol.1]. São Paulo: Editora Blucher, 2014. DOI 10.5151/foodsci-microal-288
} 
experimento também utilizou-se concentrações subinibitórias (1/2CIM e 1/4CIM), além de um experimento controle sem adição do filme e óleo essencial. As diferentes concentrações inibitórias e subinibitórias foram utilizadas nas determinações 'in vitro' de influência no crescimento micelial radial durante quatorze dias de incubação e na germinação dos esporos fúngicos. Sobre a aplicação nos frutos, foram determinados o crescimento fúngico superficial e em frutos artificialmente feridos. A quitosana e o óleo de Origanum vulgare L. apresentaram valores da concentração inibitória mínima de $10 \mathrm{mg} / \mathrm{mL}$ e de $10 \mu \mathrm{L} / \mathrm{mL}$, respectivamente, frente ao fungo estudado. A aplicação combinada de quitosana e óleo essencial de Origanum vulgare L. em diferentes concentrações inibitórias e subinibitórias causou inibição do crescimento de R. stolonifer, e da microbiota fúngica autóctone em tomates-cereja armazenados a temperatura de resfriamento e ambiente. Nos frutos feridos artificialmente e superficialmente observou-se inibição significativa frente ao controle, resultando em um aumento da vida de prateleira dos frutos. Estes resultados revelam a potencialidade da aplicação combinada de quitosana e óleo essencial em concentrações subinibitórias no controle do crescimento fungos fitopatogênicos em frutos.

Palavras-Chave: Fungos patógenos pós-colheita, Antimicrobianos, Óleo essencial

\section{Agência de Fomento:}

